Recebido em: 26/04/2020. Aprovado em: 01/08/2020.

Processo de Avaliação: Double Blind Review - SEER/OJS

e-ISSN: 2359-5876

DOI: https://doi.org/10.48075/comsus.v7i3.24665

\title{
Competitividade da Cotonicultura em Países Selecionados
}

\section{Competitiveness of Cotton Production in Selected Countries}

\begin{abstract}
Arthur Urias Marinho Cavalcante ${ }^{1}$
Silvia Parreira Tannús ${ }^{2}$

\section{Resumo}

A análise da competitividade por meio da comparação com concorrentes dos resultados econômicos de determinado setor é de suma importância para garantir permanência e rentabilidade no longo prazo. Nesse sentido, o propósito deste trabalho foi analisar mediante uso do Market Share em conjunto do Índice de Vantagens Comparativas Reveladas e do Índice de Contribuição ao Saldo a competitividade das exportações brasileiras de algodão em pluma no período de 2000 a 2017 comparando-os com os mesmos indicadores de países selecionados e verificar os resultados advindos do contencioso DS267 na OMC para este setor. Foi possível observar que durante o período analisado os países selecionados apresentaram vantagens comparativas reveladas e constatou-se que o embate judicial, assim como, a vitória brasileira do contencioso provocou aumento de competitividade no período analisado e para os períodos futuros a tendência é de resultados ainda mais expressivos, resultando em acréscimo de competitividade do produto brasileiro no mercado internacional.
\end{abstract}

Palavras-chave: Algodão; VCR; Competitividade; Contencioso DS267.

\begin{abstract}
The analysis of competitiveness through the comparison with competitors of the economic results of a certain sector is extremely important to guarantee permanence and profitability in the long term. In this sense, the purpose of this study was to analyze using the Market Share together with the Index of Comparative Advantages Revealed and the Balance Contribution Index, the competitiveness of Brazilian cotton exports in the period from 2000 to 2017 comparing them with the same selected countries indicators and verify the results from the DS267 WTO litigation for this sector. It was possible to observe that during the analyzed period, the selected countries presented revealed comparative advantages and it was found that the judicial dispute, as well as the Brazilian victory in litigation, caused an increase in competitiveness in the analyzed period and for future periods the trend is results more expressive, resulting in increased competitiveness of the Brazilian product in the international market.
\end{abstract}

Keywords: Cotton; VCR; Competitiveness; DS267; Litigation.

Cite as: (APA)

Cavalcante, A. U. M., \& Tannús, S. P. (2020). Competitividade da Cotonicultura em Países Selecionados. Revista Competitividade e Sustentabilidade, 7(3), 638-652, 2020.

\footnotetext{
${ }^{1}$ Universidade Federal de Goiás - UFG. Brasil. E-mail: arthur.marinhoc@outlook.com

${ }^{2}$ Universidade Federal de Goiás - UFG. Brasil. E-mail: silviaparreira@yahoo.com.br
} 


\section{INTRODUÇÃO}

O início do século XXI tem como uma de suas características a revolução da maneira de se fazer comércio no mundo. A globalização e o avanço tecnológico permitiram que as informações se tornassem mundiais muito rapidamente e que estivessem disponíveis onde e quando se quisesse. Esses mesmos avanços também mudaram o mercado internacional; os produtos são padronizados e distribuídos para comércios do outro lado do mundo em uma frequência inédita na história.

O comércio de commodities foi afetado por essa transformação no fluxo de informações e o Brasil, por ser um país essencialmente produtor e exportador destes produtos, teve que se adaptar para poder aproveitar os benefícios advindos dessa revolução. No mercado de commodities o preço é dado e o produtor deve se adaptar para conseguir acompanhá-lo e manter a competitividade.

Destaca-se, dentre todos os produtos do agronegócio, o algodão que movimenta quantias significativas nas balanças comerciais de diversos países e por ser o principal produto da indústria têxtil é uma commodity que merece atenção. A indústria têxtil tem um papel importante na cadeia algodoeira, pois é a uma grande absorvedora de algodão em pluma do mercado mundial e dado o seu crescimento nas últimas décadas observa-se uma tendência de aumento da necessidade de matéria-prima (Ribeiro, 2017).

O Brasil possui clima e solo adequados a cultura do algodão e por isso se destaca como o quarto maior exportador e quinto maior produtor dessa commodity, segundo dados da Associação Brasileira dos Produtores de Algodão (ABRAPA) (2019). Por ser uma cultura tão grande dentro do Brasil, estima-se que mais de 180 mil empregos são ligados diretamente ao cultivo, preparação e fiação das fibras de algodão (Neves \& Pinto, 2017).

Apenas em 2017 foram exportadas pelo Brasil 835 mil toneladas de algodão em pluma segundo dados do Database de Comércio Internacional das Nações Unidas (UN COMTRADE) (2019), movimentando mais de US\$1,36 bilhões. A quantidade exportada coloca o Brasil em uma posição de destaque, porém esta não oferece garantias de estabilidade no longo prazo, sendo assim é cada vez mais importante estar atento aos passos dos produtores concorrentes.

A história mostra que é possível produzir distorções no mercado internacional por meio da política agrícola implementada no país de origem da commodity, por isso, visando garantir permanência e competitividade no mercado internacional, o Brasil solicitou, junto à Organização Mundial do Comércio (OMC) em 2002, uma consulta para contestar a política de subsídios agrícolas norte-americana. Essa disputa internacional durou até o início de 2014, quando então chegou-se a um acordo, e os Estados Unidos pagaram compensações indenizatórias e mudaram a sua lei de apoio à agricultura, nomeada Farm Bill (Barral \& Amaral, 2015).

Desde então, estudos analisam os diferentes impactos que essa decisão teve para o agronegócio brasileiro. Barral e Amaral (2015), Dal Pai, Strassburg, Braun e Oliveira (2014) e Schnepf (2014) falaram da importância econômica e política desse contencioso, pois ele não interferiu apenas no setor de cotonicultura, mas no agronegócio mundial como um todo. Além disso, o Brasil ganhou posição de destaque junto à OMC pela força política para vencer uma disputa que se arrastou por mais de uma década.

Sendo assim, justifica-se uma avaliação econômica dos desdobramentos do contencioso para as exportações brasileiras de algodão em pluma, principalmente pelos impactos social e econômico que o setor tem no agronegócio. $O$ estudo tem por objetivo avaliar a competitividade da cotonicultura de países selecionados comparando-a com a 
brasileira no período de 2000 a 2017, por meio de indicadores selecionados e averiguar os resultados advindos do contencioso.

\section{REFERENCIAL TEÓRICO}

\subsection{Breve panorama da importância histórica da cotonicultura no Brasil}

O cultivo de algodão iniciou-se junto com a chegada dos colonizadores no Brasil, utilizando espécies nativas e importadas. Neste momento histórico, o algodão é utilizado apenas para consumo interno e seu regime de produção é pequeno e rudimentar. Um aumento da produção acontece na metade do século XVII com a corrida do ouro e a necessidade da indústria têxtil de confeccionar e vestir a crescente população (Costa \& Bueno, 2004).

Entre o fim do século XVIII e o início do século XIX a produção de algodão tornou-se voltada para o mercado inglês, devido à Revolução Industrial Inglesa, que mecanizou e modernizou a indústria têxtil com o desenvolvimento de teares mecanizados. Aproveitando essa janela de oportunidade, o Brasil produziu algodão em pluma extensivamente visando atender principalmente a demanda externa (Dal Pai et al., 2014).

$O$ início do século $X X$ caracterizou-se pelo estabelecimento de uma indústria têxtil local, capaz de absorver grande parte da produção de algodão, produção esta que deixou de ser consumida pelo mercado inglês devido à Grande Guerra. Por este motivo, houve ainda, incentivos do governo brasileiro tanto para a manutenção da produção de algodão quanto para a indústria têxtil (Costa \& Bueno, 2004).

Vieira, Lunas e Garcia (2016) afirmaram que durante a década de 1980 a cotonicultura passou por um período desafiador, com queda de produção de 1,17 milhão de toneladas para 420 mil toneladas devido a incidência da praga do bicudo nos grandes centros produtores da região nordeste. Dados de Costa e Bueno (2004) mostraram que entre 1985 e 1994, em decorrência da queda da produção e dos preços do algodão no mercado externo, mais de 800 mil postos de trabalho foram retirados dando origem ao maior êxodo rural da história do Brasil.

Durante a década de 1990 o Brasil passou para o posto de importador de algodão devido os preços artificialmente baixos promovidos por subsídios dos governos norte americanos e europeu. Neste período, o Brasil saiu do status de autossuficiente para o posto de importador de algodão do mercado externo (Barchet, Rocha, \& Dal Pai, 2016).

Segundo Ferreira Filho, Alves e Villar (2009), no início do século XXI os índices de produção tornaram a aumentar gerando excedente de oferta sendo este destinado para exportação e já na safra 2003/04 representava 6,3\% do total de algodão em pluma produzido no mundo e $3 \%$ das exportações mundiais de algodão.

Em 2017 o Brasil figurava entre os cinco maiores produtores mundiais de algodão (China, Índia, Estados Unidos e Paquistão), aparecendo também como um dos maiores exportadores mundiais. Internamente o cenário também é promissor, pois figura entre os maiores consumidores do algodão em pluma (ABRAPA, 2019).

Segundo Oliveira Neto (2017), o Brasil foi responsável, em média, por $6 \%$ da produção mundial e 7,85\% da exportação total de algodão em pluma entre os anos-safra 2006/07 a 2016/17. Estados Unidos e Índia respondem por aproximadamente $50 \%$ do total de exportações mundiais de algodão em pluma. A China é o maior produtor mundial de algodão, porém todo o montante produzido é consumido no mercado interno. 
Segundo dados de Neves e Pinto (2017), estima-se que toda a cadeia do algodão gera mais de 1,2 milhões de empregos em todo o Brasil, deste total, 180 mil empregos estão diretamente relacionados ao agronegócio, distribuídos entre o plantio, colheita e preparação da fibra para a indústria têxtil, e 1,05 milhão de empregos estão ligados à confecção e ao varejo. Por ser uma cultura altamente mecanizada, a tendência é a diminuição dos empregos diretos, mas um aumento da produtividade pode gerar mais empregos distribuídos por toda a cadeia.

O cultivo está presente em todas as regiões do país, duas se destacam: o centro-oeste, representado pelo estado do Mato Grosso, seguido por Mato Grosso do Sul e Goiás, sem plantações no Distrito Federal; e a região nordeste que é representada pela Bahia, seguida pelo Maranhão e pelo Piauí, os demais estados da região têm pouca ou nenhuma representatividade no montante cultivado. As outras regiões do país possuem pouca representatividade na área destinada ao cultivo de algodão. Em termos de área cultivada, Mato Grosso e a Bahia representam, respectivamente, $66,8 \%$ e $21,5 \%$ da área total cultivada de algodão do país (Ribeiro, 2017).

Ainda segundo Ribeiro (2017), a Bahia destaca-se na produtividade, com índices de tonelada por hectare maiores que os do Mato Grosso. Sendo assim, a região Norte-Nordeste possuí índices de produtividade maiores que a região Centro-Sul. O microclima e a topografia o qual o estado baiano está inserido também colabora para esses índices, pois permite a alta mecanização e produz uma fibra de maior qualidade.

Para a safra 2018/19 é esperado, segundo dados de Dohlman et al. (2019), do Departamento de Agricultura Norte Americano, um incremento de produção de algodão em pluma brasileiro de mais de 2 milhões de fardos (aproximadamente 440 mil toneladas) quando comparado com a safra de $2017 / 18$. A Figura 1 apresenta a comparação entre as estimativas das safras 2017/18 e 2018/19 dos principais produtores de algodão.

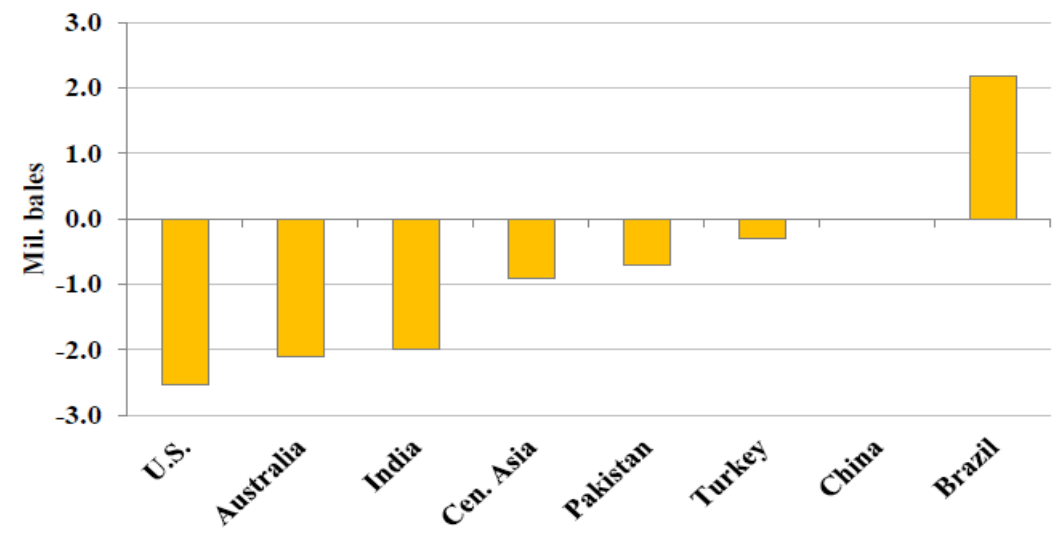

Figura 1. Comparação entre a produção mundial de algodão entre 2017/19 e 2018/19 em milhões de fardos.

Fonte: Adaptado de Dohlman et al. (2019).

Pelo quarto ano consecutivo é esperado um crescimento nas exportações de algodão; para a safra 2019/20 o crescimento esperado é de 7,9\% nas exportações mundiais segundo dados do United States Department of Agriculture (USDA) (2019). Tanto o Brasil quanto os Estados Unidos são os principais exportadores esperados para esta safra. A Figura 2 mostra o total de fardos exportados nos 4 últimos anos, a expectativa da safra 2019/20 e o percentual de crescimento quando comparado com a safra 2018/19. 


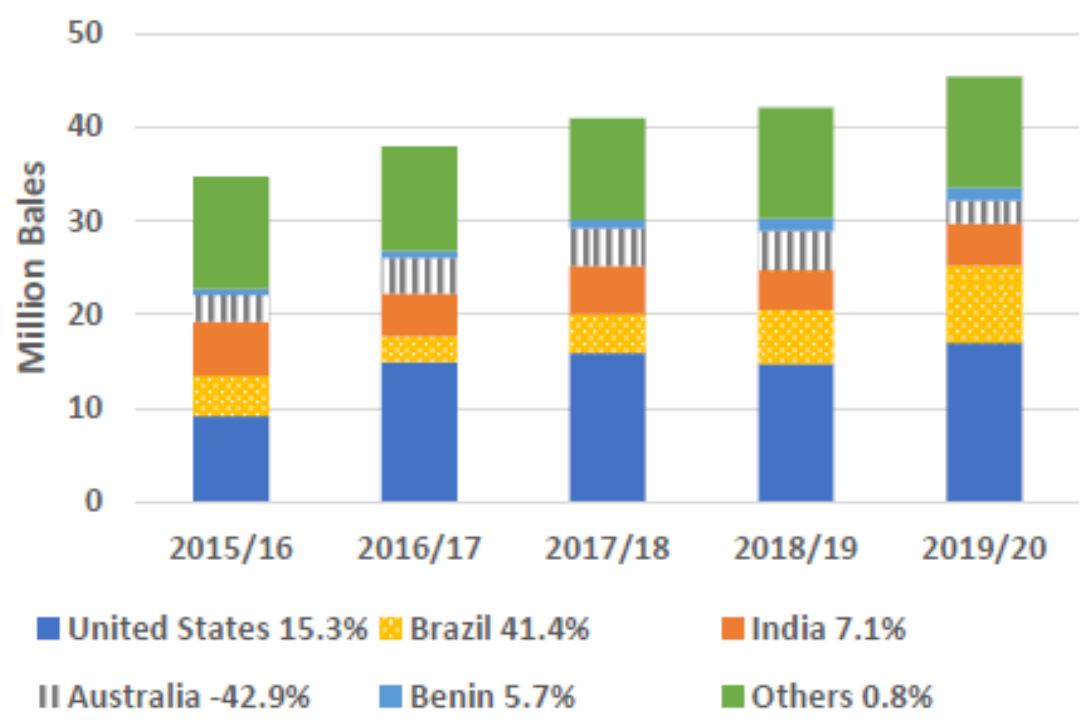

Figura 2. Total das exportações dos últimos 4 anos e previsão para a safra 2019/20 em milhões de fardos.

Fonte: Adaptado de USDA (2019).

\subsection{Contencioso de número DS267 na OMC}

Em 2002 o Brasil deu entrada a um processo na OMC contra o governo dos Estados Unidos, tendo como motivo principal a agressiva política de subsídios agrícolas seguida pelo governo norte americano. Esta política prejudicou a rentabilidade do algodão exportado pelo Brasil e demais países produtores e reduziu expressivamente a competitividade da commodity no mercado internacional, favorecendo produtores norte-americanos.

As medidas protecionistas realizadas pelo governo norte americano tinham influências diretas no comércio dessa commodity, provocando distorções no preço do mercado mundial. Países como Austrália e Argentina, além do grupo Cotton-4 (Benin, Burkina Faso, Chade e Mali) eram igualmente prejudicados (DAL PAl et al., 2014).

Ainda segundo Dal Pai et al. (2014), o Brasil é um país com grande atividade política e influencia dentro da OMC, portanto, esses países contaram com a expertise brasileira para reverter a situação e dar fim a política de incentivos fiscais e subsídios norte-americanos tornando o mercado mundial de algodão mais competitivo e igualitário.

O processo passou por diversas rodadas de julgamento na OMC. Em 2005 o Brasil requereu uma retaliação pela prática estadunidense no valor de US\$ 3 bilhões. Em 2008 houve uma arbitração da OMC para conferência deste valor, considerado alto, ficando então estabelecido uma indenização no valor de US\$ 829,3 milhões. Este valor acabou não sendo pago na sua totalidade pelos EUA nos termos acordados, e assim se sucedeu a mais uma série de rodada de negociações (SCHNEPF, 2014).

Em outubro de 2014 o contencioso se encerrou, marcando uma vitória histórica para o Brasil. Foi consolidada uma indenização aos produtores de algodão brasileiro no valor de US\$ 300 milhões, além da alteração da lei de apoio à agricultura norte americana (Farm Bill) com menores intervenções estatais e subsídios para os produtores de algodão norteamericanos (Barral \& Amaral, 2015).

É esperado com a Farm Bill norte-americana que o mercado produtor e exportador de algodão em pluma se regularize no longo prazo, fazendo com que as distorções antes provocadas no mercado internacional sejam sanadas e que outros países produtores, além do Brasil, se beneficiem dessas medidas. 


\subsection{Conceituação de competitividade}

De acordo com Schwab (2017), competitividade é o conjunto de instituições, políticas e fatores que determinam o nível de produtividade de uma economia que, por sua vez, definem o nível de prosperidade de um país. Para o crescimento da competitividade de um país é necessário um esforço coordenado de ações do Estado, da comunidade empresarial e da sociedade civil.

Para Carvalho e Guedes (2018), ser competitivo é ter êxito no ambiente econômico. Seja você uma empresa, um setor industrial ou um país, ter competitividade é ser capaz de atuar no processo competitivo o qual você se encontra durante determinado período. $A$ análise pode ser realizada sob duas dimensões temporais, é possível avaliar a competitividade de maneira ex-ante (relativo a um intervalo de tempo futuro) ou ex-post (referente a um intervalo de tempo passado).

No mercado internacional a competitividade é tratada como a capacidade de exportar bens e serviços no tempo, local, e condições desejadas pelos compradores, a preços iguais ou melhores que a concorrência e de maneira que estes supram os custos de oportunidade dos recursos empregados (Giordano, 2000).

Ferraz, Kupfer e Haguenauer (1995) afirmam que existem duas formas de se mensurar a competitividade. Uma delas é a competitividade vista pela ótica do Market Share, que mensura o alcance de uma firma ou instituição em um determinado mercado durante um determinado espaço de tempo. A outra ótica é a análise da eficiência do conjunto, que verifica o rendimento de uma firma ou instituição por meio da conversão de insumos em produto.

Pinheiro e Horta (1992) acrescentam ainda uma terceira ótica para analisar a competitividade: o conceito macro, que é centrado nas variáveis que dependem de decisões político-econômicas, tais como a taxa de câmbio e os subsídios e/ou incentivos à exportação, portanto, este modelo dá maior importância às taxas de câmbio e a relação cambio/salário.

Diversos estudos avaliam a capacidade brasileira de ser competitivo na exportação de commodities agrícolas. Aurélio Neto (2018) avaliou a competitividade brasileira na exportação de carne bovina mostrando que o Brasil figura entre os maiores produtores e exportadores de carne bovina do mundo, tendo alta qualidade e bom preço resultando em um mercado promissor e competitivo.

A importância do complexo-soja foi analisada por Faccin e Castillo (2019) que verificou o impacto desta cultura na economia nacional. A alta demanda da commodity juntamente com o clima e terreno favorável mostrou a capacidade do agricultor brasileiro de se adaptar rapidamente ao cenário internacional, tornando o Brasil um dos principais exportadores de soja no mundo e com grandes áreas extremamente especializadas nesta cultura. Essa dinâmica mostrou como o agronegócio brasileiro é competitivo neste setor.

Uma avaliação da competitividade do milho brasileiro no mercado internacional por meio de indicadores selecionados foi realizada por Ferreira e Capitani (2017) e concluiu que a cultura do milho foi, no período analisado, um dos mais dinâmicos e competitivos do mercado brasileiro, apresentando taxas de crescimento positivas em todos os indicadores analisados.

Franck, Coronel, Mygre Silva e Rodrigo Silva (2015) avaliaram a competitividade das exportações de minério de ferro do Brasil para a China, mostrando que o minério de ferro brasileiro é um produto de grande demanda chinesa e que o mercado é promissor, porém apresenta desafios relacionados ao custo logístico e alta competitividade do produto concorrente australiano. 
Exemplos como os citados enfatizam e mostram a capacidade do Brasil de ser um grande exportador de commodities diversas, seja as ligadas ao agronegócio, como soja, milho, algodão, trigo, café, carne bovina, carne de aves; assim como as commodities minerais, como minério de ferro, níquel, nióbio e fosfato.

A importância do estudo da competitividade de um determinado setor ou cadeia produtiva se dá pelo conhecimento potencial acerca do mercado, sejam os potenciais concorrentes e como estes atuam no mercado, as barreiras à entrada, o tamanho de mercado que é possível ocupar, as projeções futuras do comportamento do setor.

Para este estudo, considerou-se a interpretação de competitividade mais adequada aquela que diz que um processo produtivo é competitivo quando ele, além de atender as demandas do comprador, ainda é capaz de produzir rentabilidade e manter a participação no mercado, tanto interno quando externo.

\section{METODOLOGIA}

Para analisar a competividade do total das exportações dos principais países produtores de algodão durante o período de 2000-2017 foi utilizado a Índice de Vantagem Comparativa Revelada (IVCR). Já para analisar a fatia de mercado que estes países possuem nas exportações de algodão foi utilizado o Market-Share (MS). O Índice de Contribuição ao Saldo (CS) tem por objetivo corroborar o apresentado no IVCR sendo este analisado por outra ótica.

\section{1 Índice de vantagens comparativas reveladas}

A definição de Vantagem Comparativa Revelada foi introduzida por Balassa (1965) para analisar a competitividade de um país, desde então este conceito vem sendo aplicado para esse tipo de análise.

Segundo Siqueira (2011), o indicador de Vantagens Comparativas Reveladas utiliza dados de pós-comércio, ou seja, o cálculo é balizado em valores já concretizados de exportações. A principal característica desse método é a análise das diferenças de custos relativos existentes entre países, direcionando, assim, a produção de determinados produtos e a importação de outros.

Para Fernandes e Santos (2011), o IVCR relaciona as exportações de um determinado produto de um país com as exportações mundiais desse mesmo produto, permitindo assim, comparar a participação relativa de um determinado produto no comercio internacional.

A equação (1) apresenta a fórmula da IVCR utilizada neste artigo.

$$
I V C R_{i j}=\frac{X_{i j} / X_{j}}{X_{i} / X}
$$

em que $\mathrm{Xij}$ representa as exportações do produto $\mathrm{i}$, pelo país j; $\mathrm{Xj}$ representa as exportações totais do país j; $\mathrm{Xi}$ representa as exportações mundiais do produto $\mathrm{i}$; $\mathrm{X}$ representa as exportações mundiais totais.

O IVCR pode apresentar três resultados distintos:

- IVCR > 1, o produto analisado possui vantagem comparativa revelada;

- IVCR < 1, o produto analisado possui desvantagem comparativa revelada;

- IVCR = 1, neste caso, não existe excedente a ser exportado, o que representa que a produção local atende à demanda ou não existe demanda interna para o produto. 


\subsection{Market Share (MS)}

A equação (2) apresenta a fórmula do Market Share utilizada.

$$
M S=\frac{X_{i j}}{X_{i}}
$$

em que Xij representa as exportações do produto i, pelo país j; Xi representa as exportações mundiais do produto $\mathrm{i}$.

O resultado da equação (2) é a porcentagem de mercado do produto (i) que o país analisado (j), possui em relação a todo o comercio internacional do mesmo produto. Quanto maior o percentual, maior a fatia do mercado analisado o país possuí.

\section{3 Índice de Contribuição ao Saldo (ICS)}

Tendo em vista que o Índice de Vantagens Comparativas Reveladas considera apenas o fluxo de exportações de um país para medir a capacidade competitiva de um país, foi proposto por Lafay (1990) o Índice de Contribuição ao Saldo, que leva em consideração também o saldo comercial de um país. A equação (3) apresenta a fórmula do Índice de Contribuição ao Saldo.

$$
I C S_{i j}=\frac{1000}{P I B_{j}} *\left\{\left(X_{i j}-M_{i j}\right)-\left[\left(X_{j}-M_{j}\right) \frac{\left(X_{i j}+M_{i j}\right)}{\left(X_{j}+M_{j}\right)}\right]\right\}
$$

em que Xij representa as exportações do produto i, pelo país j; Xj representa as exportações totais do país j; Mij representa as importações do produto i, pelo país j; Mj representa as importações totais do país j; PIBj representa o Produto Interno Bruto do país j.

O ICS pode apresentar dois resultados distintos:

- ICS $>0$, o produto analisado possui vantagem comparativa revelada;

- ICS $<0$, o produto analisado não possui vantagem comparativa revelada.

O Índice de Contribuição ao Saldo, assim como o IVCR, é um indicador ex post, ou seja, pós-consumo. Segundo Cunha e Xavier (2010), o indicador procura expressar as vantagens comparativas baseadas nos saldos comerciais e não apenas no fluxo de exportações. Em caso de ICS positivo pode-se afirmar que as exportações do setor contribuem positivamente para geração de saldo comercial do país.

\subsection{Fonte de dados}

A commodity analisada foi a de número SITC (Standard International Trade Classification) 2631 (Rev. 3) que engloba o Algodão Cru. Os dados foram extraídos da plataforma online do COMTRADE (United Nations International Trade Statistics Database Banco de Dados de Estatísticas do Comércio Internacional das Nações Unidas). Foram necessários os dados de importação e exportação gerais mundo, e os dados de importação e exportação da commodity dos principais países importadores e exportadores. Para o valor do PIB (Produto Interno Bruto) dos países, foi utilizada a base de dados online do FMI (Fundo Monetário Internacional). O período analisado foi de 2000 até 2017, por ser 2017 o último com a consolidação dos dados disponíveis. 


\section{APRESENTAÇÃO E ANÁLISE DOS RESULTADOS}

Os resultados obtidos por meio do cálculo do Market Share mostram que, no ano de 2017, o Brasil ocupou a quarta posição no ranking dos maiores exportadores de algodão em pluma do mundo, estando atrás apenas dos Estados Unidos, Índia e Austrália, respectivamente. A Tabela 1 mostra a evolução da fatia de mercado destes países desde o início do século XXI.

Tabela 1

Market share dos principais países exportadores de algodão em pluma no período de 20002017 (em \%)

\begin{tabular}{ccccc}
\hline Período & Brasil & EUA & Índia & Austrália \\
\hline 2000 & 0,50 & 29,97 & 0,14 & 13,93 \\
2001 & 2,57 & 36,06 & 0,17 & 17,16 \\
2002 & 1,66 & 36,27 & 0,12 & 12,04 \\
2003 & 2,48 & 44,35 & 0,48 & 7,83 \\
2004 & 4,18 & 43,77 & 1,86 & 7,32 \\
2005 & 5,42 & 47,30 & 3,93 & 9,27 \\
2006 & 3,76 & 50,10 & 10,77 & 8,50 \\
2007 & 5,23 & 47,22 & 16,93 & 4,81 \\
2008 & 6,94 & 48,18 & 16,14 & 3,77 \\
2009 & 8,91 & 44,10 & 13,11 & 5,49 \\
2010 & 6,09 & 42,49 & 22,02 & 7,10 \\
2011 & 8,06 & 42,53 & 17,19 & 13,29 \\
2012 & 11,16 & 33,03 & 19,35 & 14,42 \\
2013 & 6,41 & 32,42 & 26,17 & 14,56 \\
2014 & 9,93 & 32,20 & 20,66 & 13,26 \\
2015 & 12,74 & 38,42 & 18,38 & 8,03 \\
2016 & 12,25 & 39,90 & 13,56 & 12,17 \\
2017 & 10,39 & 44,58 & 12,80 & 12,37 \\
\hline
\end{tabular}

Fonte: Dados da pesquisa.

Percebe-se que durante todo o período analisado o Brasil obteve um Market Share médio de 6,6\%, e que entre 2000 e 2015 a participação nas exportações mundiais cresceu em 25 vezes, mostrando a importância desta cultura e o empenho dos produtores brasileiros em atender a demanda interna e ainda produzir excedente para o mercado externo. Quando comparado ao mesmo período, os EUA ampliaram sua fatia em apenas 1,2 vezes, Índia em mais de 130 vezes e a Austrália reduziu pela metade a sua participação nas exportações de algodão em pluma.

É notável que durante toda a série, mas principalmente em 2006, os Estados Unidos foram o principal player deste mercado, respondendo por um Market Share de $50 \%$ das exportações totais mundiais. Em 2017 o país alcançou 44,6\% do total de exportações, a Índia foi a segunda maior exportadora da commodity com 12,8\%, Austrália, com 12,4\% e Brasil com 10,4\% e a Grécia, que é a 50 maior exportadora mundial, com uma fatia de 3\%. A Figura (3) mostra em maiores detalhes o percentual desses números. 


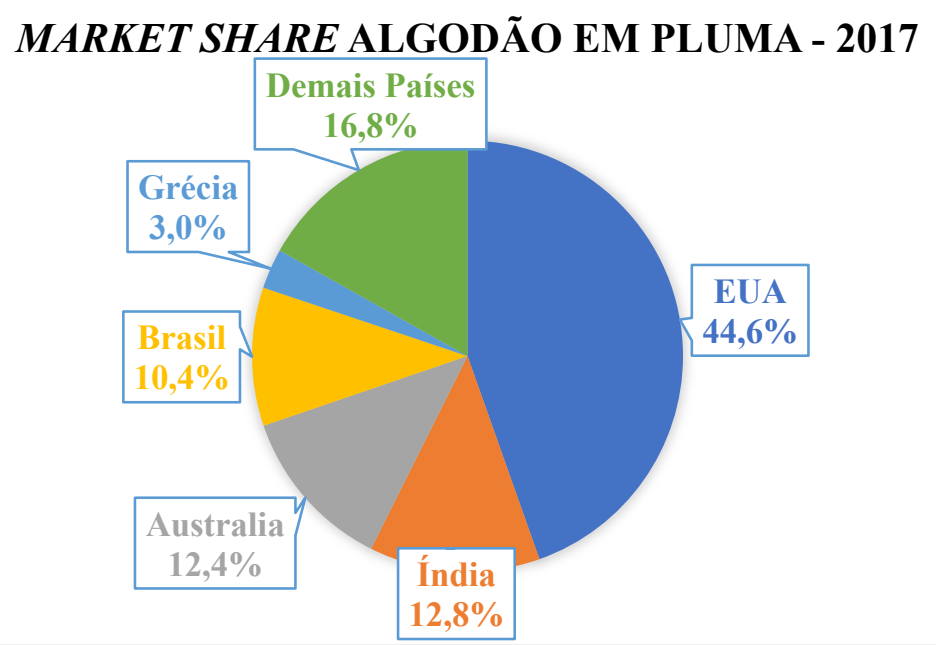

Figura 3. Principais detentores de fatias do mercado de algodão em pluma - 2017.

Fonte: Dados da pesquisa.

Recorta-se o mercado exportador do Brasil e da Índia devido suas semelhanças, seja pelo tamanho do Market Share ou pelas políticas econômicas no que diz respeito ao comércio de commodities agrícolas e compara-se a competitividade, via IVCR e ICS destes com o mercado norte-americano, pelo seu grande volume e sua política ostensiva de subsídios agrícolas.

A Tabela 2 mostra a série de 2000 a 2017 do Índice de Vantagens Comparativas Reveladas dos três países recortados para o estudo. É notável que os três países possuem valores acima da unidade na maior parte do período do analisado, indicando que este mercado possui vantagens comparativas reveladas nas balanças destes países.

Tabela 2

Índice de vantagens comparativas reveladas no período de 2000-2017

\begin{tabular}{cccc}
\hline Período & Brasil & EUA & Índia \\
\hline 2000 & 0,579 & 2,426 & 0,202 \\
2001 & 2,682 & 3,010 & 0,242 \\
2002 & 1,757 & 3,350 & 0,149 \\
2003 & 2,468 & 4,461 & 0,595 \\
2004 & 3,904 & 4,852 & 2,208 \\
2005 & 4,651 & 5,339 & 3,983 \\
2006 & 3,248 & 5,745 & 10,572 \\
2007 & 4,430 & 5,533 & 15,805 \\
2008 & 5,510 & 5,824 & 13,950 \\
2009 & 7,149 & 5,121 & 9,102 \\
2010 & 4,531 & 4,998 & 15,021 \\
2011 & 5,665 & 5,164 & 10,254 \\
2012 & 8,269 & 3,841 & 12,005 \\
2013 & 4,958 & 3,845 & 14,544 \\
2014 & 8,211 & 3,700 & 12,108 \\
2015 & 10,747 & 4,123 & 11,205 \\
2016 & 10,361 & 4,310 & 8,163 \\
2017 & 7,815 & 4,726 & 7,125 \\
\hline
\end{tabular}

Fonte: Dados da pesquisa. 
O destaque fica para o período pós-2008, quando se encerrou a primeira rodada de negociações do contencioso DS267; mesmo com o não pagamento da totalidade das sanções do governo norte americano percebe-se que para o Brasil houve um aumento significativo do nível de competitividade neste setor. Para o mercado indiano, em contrapartida, houve redução dos níveis competitividade.

A Tabela 3 apresenta os resultados da série de 2000 a 2017 do Índice de Contribuição ao Saldo. Assim como o IVCR, durante a maior parte do período os países apresentaram resultados positivos, indicando que o mercado algodoeiro contribuiu positivamente ao saldo e que existem vantagens comparativas reveladas no período. Como pode ser observado através da comparação entre os dados o ICS corrobora com as informações fornecidas pelo IVCR.

Tabela 3

Índice de contribuição ao saldo no período de 2000-2017

\begin{tabular}{cccc}
\hline Período & Brasil & EUA & Índia \\
\hline 2000 & $-0,440$ & 0,225 & $-0,590$ \\
2001 & 0,095 & 0,249 & $-0,701$ \\
2002 & 0,020 & 0,236 & $-0,475$ \\
2003 & $-0,021$ & 0,377 & $-0,457$ \\
2004 & 0,184 & 0,453 & 0,022 \\
2005 & 0,330 & 0,396 & 0,298 \\
2006 & 0,134 & 0,422 & 1,081 \\
2007 & 0,210 & 0,402 & 1,468 \\
2008 & 0,349 & 0,410 & 1,428 \\
2009 & 0,361 & 0,282 & 0,781 \\
2010 & 0,320 & 0,464 & 2,061 \\
2011 & 0,412 & 0,651 & 2,172 \\
2012 & 0,814 & 0,462 & 2,315 \\
2013 & 0,431 & 0,397 & 2,642 \\
2014 & 0,533 & 0,300 & 1,434 \\
2015 & 0,675 & 0,259 & 0,907 \\
2016 & 0,551 & 0,257 & 0,356 \\
2017 & 0,507 & 0,364 & 0,471 \\
\hline
\end{tabular}

Fonte: Dados da pesquisa.

É importante frisar que de 2014 em diante, período após o fim do contencioso e início da nova política de subsídios agrícolas norte americana, tanto o seu IVCR quanto o ICS apresentaram tendência de queda, e em contrapartida estes indicadores aplicados ao mercado brasileiro apresentaram significativo aumento. Isso mostra que a disputa comercial trouxe resultados a cotonicultura brasileira.

A partir do ano de 2016 a cotonicultura brasileira foi marcada pelo protagonismo dos seus níveis de competitividade quando comparado aos demais países selecionados. A Figura 4 mostra o comparativo dos anos de 2016 e 2017 dos indicadores IVCR e ICS aplicado aos três mercados estudados. O do valor do indicador de vantagens comparativas reveladas e da contribuição ao saldo mostram que o mercado brasileiro conseguiu superar o seu principal concorrente e a vitória do contencioso foi capaz de reduzir as disparidades do mercado internacional. 
IVCR - 2016 e 2017

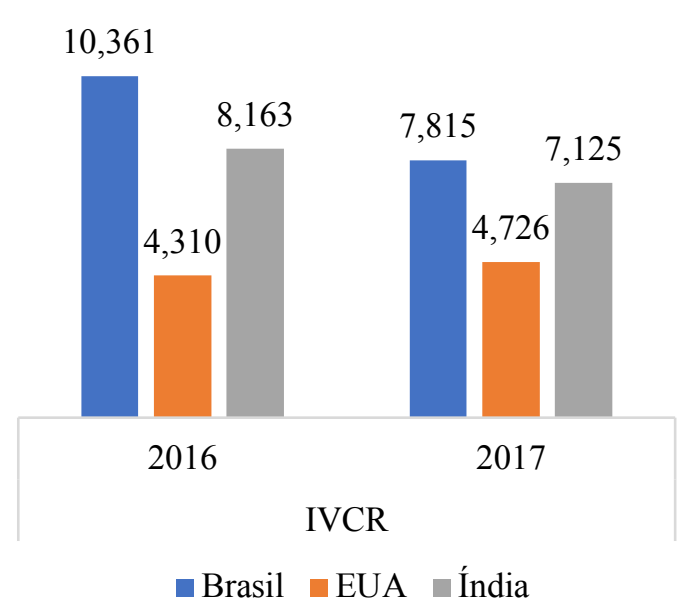

ICS - 2016 e 2017

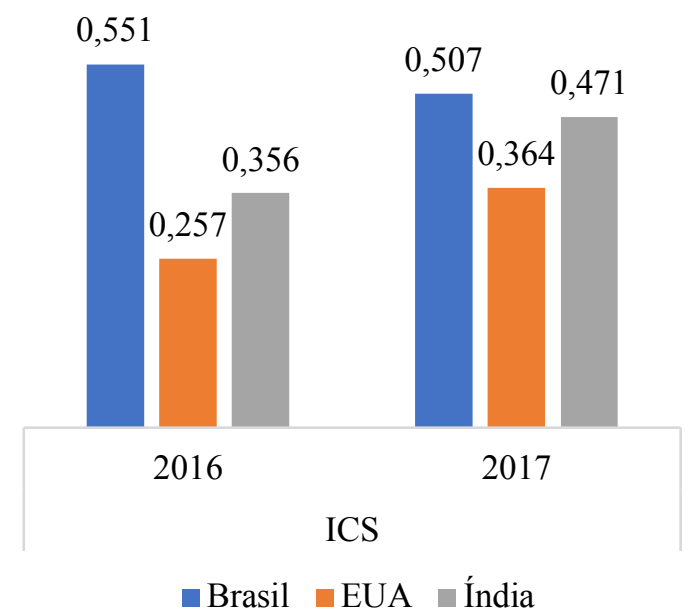

Figura 4. Comparativo do IVCR e ICS dos anos de 2016 e 2017 do Brasil, EUA e Índia. Fonte: Dados da pesquisa.

Quando se analisa os resultados do IVCR em conjunto com o ICS é possível inferir que a cultura algodoeira possuí grande expressividade no saldo das exportações e na balança comercial dos países selecionados. Os números mostram que todos os países analisados possuem vantagens comparativas reveladas e que a exportação de algodão em pluma contribui positivamente à saldo comercial do país.

Outro fator importante a ser destacado é que a melhora do desempenho da cotonicultura brasileira não se deve apenas à vitória no contencioso, mas também aos investimentos do governo em agências de tecnologia e pesquisa como a Empresa Brasileira de Pesquisa Agropecuária (Embrapa) que faz melhoramentos genéticos e trabalha para obter maiores índices de produtividade por hectare. Existem ainda vantagens advindas das condições climáticas e solo favorável, além de altos investimentos em mecanização, tecnologia e controle de pragas.

Segundo Santos (2019), representante da Embrapa Algodão, é esperado um incremento na demanda por fibras naturais devido à elevação da renda e a convergência mundial para o consumo de produtos orgânicos em oposição às fibras sintéticas e em resposta a isso o Brasil é o único produtor de algodão que tem disponibilidade para crescimento em produtividade e área cultivada, tornando um dos principais players nesse mercado.

Santos (2019) afirma ainda, que é esperado para a safra 2019/20 uma produção de 2,7 milhões de toneladas de algodão, sendo 1,7 milhão de toneladas destinadas à exportação. Tudo isso graças ao aumento da produtividade média, que cresceu $20 \%$ nos últimos 10 anos. O Valor Bruto da Produção (VPB) cresceu $131 \%$ nos últimos três anos, mostrando o quão promissor esta cultura está sendo para o agronegócio brasileiro.

A tendência dos indicadores brasileiros é de apresentar crescimento ante ao quadro apresentado para as safras seguintes e têm-se que no longo prazo os países produtores mais competitivos no cenário mundial ganhem destaque tornando ações como a brasileira contra governos protecionistas e intervencionistas menos necessárias. Com isso reduz-se as distorções do mercado externo e torna o comércio de algodão em pluma mais competitivo para aqueles que melhor desempenham essa atividade. 


\section{CONSIDERAÇÕES FINAIS}

Este artigo analisou a competitividade das exportações de algodão em pluma do Brasil comparando-a as exportações do mesmo produto da Índia e Estados Unidos, no período de 2000 a 2017. Para tal, utilizou-se o Market Share, o Índice de Vantagens Comparativas Reveladas (IVCR) e o Índice de Contribuição ao Saldo (ICS). Percebe-se que os países selecionados apresentaram IVCR $>1$ e ICS $>0$ para grande maioria do período avaliado.

Observa-se que o setor apresentou franca expansão, tendo um crescimento no volume mundial exportado de $46 \%$ entre 2000 e 2017. O mercado de produção de algodão em pluma para exportação mundial é promissor, pois há crescimento esperado dos níveis de exportação representando um acrescimento na demanda internacional por este produto. Como sinalizado, existe uma preferência mundial por fibras naturais em detrimento das sintéticas, o que coloca o algodão em posição de destaque entre as commodities.

Constatou-se que durante o período analisado o mercado cotonicultor brasileiro não apresentou apenas crescimento de competitividade como também se tornou o mais competitivo exportador entre os países comparados, uma vez que no último período analisado (2017) tanto o IVCR como ICS calculado apresentou resultados maiores que dos demais países comparados. Entre 2000 e 2017, os produtores ficaram mais servidos de salvaguardas, tais como cultivares melhores adaptados, expertise no cultivo de algodão, acréscimo de tecnologia aplicado ao cultivo, além do clima e solo favoráveis ao cultivo.

É notável que o fim contencioso na OMC trouxe, no curto prazo, impactos positivos e significativos para os países produtores de algodão e em especial para os produtores brasileiros. Espera-se que a longo prazo o mercado brasileiro torne-se ainda mais competitivo e que seja capaz de enfrentar as distorções do mercado internacional com maior facilidade, tendo em vista a evolução que a cultura passou ao longo das duas últimas décadas.

Além dos benefícios para a cotonicultura, a vitória no contencioso mostra que o Brasil tem a expertise necessária para mediar situações conflituosas no mercado internacional o que pode ser útil para acertar mais pontos de desvio e distorções que os demais governos provocam no mercado internacional, com isso tornando o mercado mais livre e com menores barreiras à entrada.

É importante destacar que o estudo avalia a competitividade sob a ótica do MarketShare, ou seja, a participação de mercado do conjunto de vendedores em um mesmo país em dado momento do tempo. Com base nisso, é válida uma proposta de análise complementar da competitividade sob a ótica de produtividade e capacidade de transformar matérias-primas em produtos acabados com menor custo e tempo e melhor qualidade e eficiência.

O estudo se constitui com de informações importantes para avaliadores de políticas públicas e privadas voltadas a cotonicultura. Pois avaliou a recuperação da cotonicultura brasileira em relação aos seus pares internacionais no decorrer de 15 anos, mostrando a capacidade de cultivo e processamento adquirida na medida em que comparou o desempenho brasileiro frente aos principais produtores e exportadores.

\section{REFERÊNCIAS}

Associação Brasileira dos Produtores de Algodão. (2019). Produção mundial de algodão.

Recuperado de http://www.abrapa.com.br/Paginas/dados/producao-mundialalgodao_backup2017.aspx. 
Aurélio Neto, O. (2018). O Brasil no mercado mundial de carne bovina: análise da competitividade da produção e da logística de exportação brasileira. Ateliê GeoFigura, 12(2), 183-204.

Balassa, B. (1965). Trade liberalization and 'revealed' comparative advantage. The Manchester School, 33(2), 99-123.

Barchet, I., Rocha, \& A. A., Dal Pai, C. (2016). Mudança estrutural o setor cotonicultura brasileiro: uma análise da territorialização no cerrado brasileiro e do impacto do contencioso do algodão. Revista Brasileira de Planejamento e Desenvolvimento, 5(1), 625.

Barral, W., \& Amaral, R. (2015). Fim do contencioso do algodão: lições de uma disputa na OMC. Revista Brasileira de Comércio Exterior, 122, 1-4.

Carvalho, E. G., \& Guedes, S. N. R. (2018). A competitividade internacional: notas para uma abordagem não ortodoxa. Brazil. J. Polit. Econ., 38(4), 731-739.

Costa, S. R., \& Bueno, M. G. (2004). A saga do algodão: das primeiras lavouras à ação na $O M C$. Rio de Janeiro: Insight Engenharia.

Cunha, S. F., \& Xavier, C. L. (2010). Fluxos de investimento direto externo, competitividade e conteúdo tecnológico do comércio exterior da China no início do século XXI. Rev. Econ. Polit., 30(3), 491-510.

Dal Pai, C., Strassburg, U., Braun, M. B. S., \& Oliveira, N. M. (2014, julho). Política comercial e competitividade das exportações brasileiras de algodão: uma reflexão sobre o contencioso na OMC. Anais do Congresso SOBER - Sociedade Brasileira de Economia, Administração e Sociologia Rural, Goiânia, GO, Brasil, 52. Recuperado de http://icongresso.itarget.com.br/tra/arquivos/ser.4/1/3396.pdf.

Dohlman, E. et al. (Org.). (2019). Cotton outlook. Recuperado de https://www.usda.gov/oce/forum/past_programs/2019/Outlooks.htm.

Faccin, A. C. T. M., \& Castillo, R. (2019). A centralidade do complexo-soja na economia brasileira e a manutenção da produção agrícola extravertida: análise da soja em Mato Grosso do Sul. Geosul, 34(71), 111-129.

Fernandes, R., \& Santos, C. (2011). Competitividade das exportações sucroalcooleiras do Estado de São Paulo. Revista de Política Agrícola, 20(4), 21-36.

Ferraz, J. C., Kupfer, D., \& Haguenauer, L. (1995). Made in Brazil - desafios competitivos para a indústria. Rio de Janeiro, RJ: Campus.

Ferreira Filho, J. B. S., Alves, L. R. A., \& Villar, P. M. (2009). Estudo da competitividade da produção de algodão entre Brasil e Estados Unidos - safra 2003/04. Rev. Econ. Sociol. Rural, 47(1), 59-88.

Ferreira, B., \& Capitani, D. (2017). Competitividade do milho brasileiro no mercado internacional. Revista de Política Agrícola, 26(2), 86-99.

Franck, A. G. S., Coronel, D. A., Silva, Mygre L., \& Silva, Rodrigo A. (2015). Competitividade das exportações australianas e brasileiras de minério de ferro para a China (1999-2014). Revista NECAT, 4(8), 28-43.

Giordano, S. R. (1999). Competitividade regional e globalização (Tese de doutorado) Faculdade de Filosofia, Letras e Ciências Humanas, Universidade de São Paulo, São Paulo, SP, Brasil.

Lafay, G. (1990). La mesure des avantages comparatifs révélés: exposé de la méthodologie du CEPII. In Économie prospective internacionale (pp. 27-43). 
Neves, M. F., \& Pinto, M. J. A. (Org.). (2019). A cadeia do algodão brasileiro: safra 2016/2017 - desafios e estratégias. Recuperado de http://www.abrapa.com.br/Documents/A\%20Cadeia\%20do\%20Algoda\%CC\%83o\%20Br asileiro.pdf.

Oliveira Neto, A. A. (Org.). (2017). A cultura do algodão: análise dos custos de produção e da rentabilidade nos anos-safra 2006/07 a 2016/17. Brasília: Conab.

Pinheiro, A. C., \& Horta, M. H. (1992). A competitividade das exportações brasileiras no período 1980/88. Rio de Janeiro: IPEA.

Ribeiro, L. S. (Org.). (2017). Indicadores da agropecuária (6a ed.). Brasília, DF: Conab.

Santos, E. (2019). Aumento da produção de algodão no Brasil traz novos desafios para a pesquisa, aponta documento da Embrapa. Brasília, DF: Embrapa.

Schnepf, R. (2014). Status of the WTO Brazil - U.S cotton case. Washington, DC:

Congressional Research Service. Recuperado de http://nationalaglawcenter.org/wpcontent/uploads/assets/crs/R43336.pdf.

Schwab, K. (Org.). (2017). The global competitiveness report 2017-2018: insight report, world economic forum. Recuperado de https://www.weforum.org/reports/the-globalcompetitiveness-report-2017-2018.

Siqueira, K. B. (2011). Vantagens comparativas reveladas do Brasil no comércio internacional de lácteos. Juiz de Fora, MG: Embrapa Gado de Leite.

UN Comtrade. (2019). United nations trade statistics database. Recuperado de https://comtrade.un.org/data/.

United States Department of Agriculture. (2019). Cotton: world markets and trade: record world consumption helps lower stocks in 2019/20. Recuperado de https://usda.library.cornell.edu/concern/publications/kp78gg36g?locale=en.

Vieira, A., Lunas, D., \& Garcia, J. (2016). Ambiente institucional na dinâmica da cotonicultura brasileira. Revista de Política Agrícola, 25(2), 53-66. 